\title{
ACASO E PROBABILIDADES NOS ANOS INICIAIS: POTENCIAL DOS JOGOS COMO MEDIADORES NA CONSTRUÇÃO DO CONHECIMENTO
}

\author{
ACCOUNT AND CHALLENGES IN INITIAL YEARS: POTENTIAL OF \\ GAMES AS MEDIATORS IN CONSTRUCTION OF KNOWLEDGE
}

\author{
Keli Cristina Conti ${ }^{1}$ \\ Sandra Gonçalves Vilas Bôas ${ }^{2}$
}

\begin{abstract}
Resumo: No Brasil, desde a publicação dos Parâmetros Curriculares Nacionais (1997), os conteúdos de Estatística e Probabilidade fazem parte dos currículos e foram reafirmados na Base Nacional Comum Curricular $(2017,2018)$. Neste artigo, objetiva-se apresentar um breve contexto histórico sobre Probabilidade e Acaso. Outro aspecto será a discussão da questão curricular envolvendo essas duas temáticas as quais podem ser trabalhadas nos Anos Iniciais do Ensino Fundamental ( $1 .^{\circ}$ ao $5 .^{\circ}$ ano), apresentar preâmbulo sobre o potencial dos jogos, exemplificar propostas para a sala de aula que permita trabalhar noções iniciais de probabilidade por meio de um jogo e de atividades investigativas, introduzindo assim as primeiras noções para posteriormente aprofundá-las nos anos seguintes. Esperamos subsidiar também o trabalho do professor e desmistificar o ensino de Probabilidade com as crianças nos Anos Iniciais do Ensino Fundamental.
\end{abstract}

Palavras-chave: Educação Estatística; Probabilidade; Jogos; Formação de professores; Currículo.

\begin{abstract}
In Brazil, since the publication of the National Curricular Parameters (1997), the contents of Statistics and Probability are part of the curricula and were reaffirmed in the National Curricular Common Base $(2017,2018)$. This article aims to present a brief historical context about Probability and Chance. Another aspect will be the discussion of the curriculum issue involving these two themes which can be worked on in the Early Years of Elementary School (1st to 5th grade), presenting preamble about the potential of games, exemplifying proposals for the classroom that allow you to work on initial notions of probability through play, and investigative activities, thus introducing the first notions and then deepening them into subsequent years. We hope to subsidize the work of the teacher and demystify the teaching of Probability with the children in the Initial Years of Elementary School.
\end{abstract}

Keywords: Statistical Education; Probability; Games; Teacher training; Curriculum.

\section{Introdução}

Nesse artigo, partindo da Base Nacional Comum Curricular (BRASIL, 2017, 2018), no que diz respeito aos Anos Iniciais (1. ${ }^{\circ}$ ao 5. ${ }^{\circ}$ ano - crianças de 6 a 10 anos) e à

\footnotetext{
${ }^{1}$ Doutora em Educação pela Universidade Estadual de Campinas (UNICAMP). Professora adjunta na Universidade Federal de Minas Gerais (UFMG), Belo Horizonte, MG, Brasil. E-mail: keli.conti@gmail.com

${ }^{2}$ Doutora em Educação Matemática pela Universidade Estadual Paulista Júlio Mesquita Filho (UNESP). Professora da Universidade de Uberaba - (UNIUBE). Uberlândia, MG, Brasil. E-mail: sandraavilasboas@yahoo.com.br
} 
DOI: http://dx.doi.org/10.33238/ReBECEM.2019.v.3.n.2.22625

área de conhecimento Matemática, que também tem como componente curricular a Matemática, vamos nos ater à Unidade Temática Probabilidade e Estatística, com destaque apenas para a Probabilidade.

Inicialmente, apresentamos um pequeno contexto histórico sobre a questão do acaso, logo em seguida, o item curricular em relação ao ensino de Estatística e Probabilidade. Detalharemos a BNCC no que diz respeito a Probabilidade, e na sequência apontaremos o potencial dos jogos como disparador em um trabalho com a temática: por meio do Jogo "Campeonato dos números". Além, dessa ação, outras três tarefas, de natureza investigativa, serão aplicadas com objetivo de ampliar as habilidades relativas as temática nos Anos Iniciais do Ensino Fundamental. Acredita-se que dessa maneira, o trabalho do professor possa ser subsidiado, ao apresentar possibilidades que permitem colocar a BNCC em ação.

\section{A teoria das probabilidades como modelo matemático do acaso - Aspectos históricos e filosóficos}

Grau ou a medida da possibilidade de um evento ou de uma classe de eventos. Nesse sentido, Probabilidade sempre supõe uma alternativa, e é a escolha ou preferência por uma das alternativas possíveis. Do ponto de vista quantitativo ela é expressa com um número real cujos valores vão de 0 a 1 . Nessa perspectiva, a probabilidade procura fornecer o grau ou a medida da possibilidade de um evento ou de uma classe de eventos.

A abordagem matemática do acaso, do azar e do risco só se iniciou há pouco mais de 500 anos, pois, segundo Silva (2002), houve uma grande demora até que ligações entre os jogos de azar e a Matemática fossem notadas. Esse autor aponta para três fatores principais:

\footnotetext{
1) os primeiros dados não possuíam um balanceamento perfeito: isso impedia que fosse percebida alguma regularidade dos eventos possíveis;

2) o fato de que as idéias de acaso e indeterminismo foram estranhas ao raciocínio humano durante muitos séculos;

3) os acontecimentos terrenos eram dirigidos por 'Deus' ou pelos deuses: assim, se o resultado do lançamento de um dado era este ou aquele, isto era simplesmente a manifestação da(s) vontade(s) divina(s) (SILVA 2002, p. 34$35)$.
}

Os primeiros estudos sobre probabilidade se iniciaram no século XVI, com matemático e jogador italiano, Jerónimo Cardano (1501-1576) o qual escreveu um pequeno manual de jogos de azar "Liber de Ludo Aleae" (O livro dos jogos de Azar), talvez o primeiro sobre probabilidades, que analisa jogos e possibilidades. Cardano foi o 


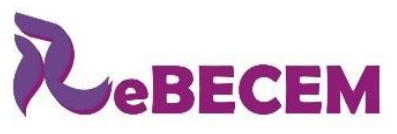

Revista Brasileira de Educação em

Ciências e Educação Matemática

DOI: http://dx.doi.org/10.33238/ReBECEM.2019.v.3.n.2.22625

primeiro a introduzir técnicas combinatórias para calcular a quantidade de possibilidades favoráveis num evento aleatório. Também, o primeiro a fazer observações do conceito probabilístico de um dado honesto, afirmando que "ao jogar dados, a chance de se obter um, três ou cinco era a mesma de se obter dois, quatro ou seis".

No entanto, grande parte dos autores refere-se a Pascal (1623/1662) e Fermat (1601/1665) como sendo os fundadores do Cálculo das Probabilidades.

O primeiro grande problema das Probabilidades foi proposto por Chevalier de Méré ${ }^{3}$ a Pascal, surgiu na corte dos reis de França onde a nobreza se divertia, entre outras atividades, a jogar. Tratava-se da procura da compreensão de um determinado jogo com três dados de que Méré não conseguia entender os resultados empiricamente observados. Pascal e Fermat, separadamente, encontraram a solução do problema, mas a solução de Pascal era muito específica enquanto que a de Fermat constituiu talvez o primeiro método geral das probabilidades. Naquele problema surgiam duas situações que se punham com a mesma probabilidade, mas que diferiam na verificação empírica da análise de frequência. Começa aqui a surgir a ideia da Lei dos Grandes Números e a identificação "automática" entre probabilidade e frequência num elevado número de provas.

Neste sentido, pode-se dizer que Pascal e Fermat levavam em conta as regularidades macroscópicas observadas em jogos de azar (fenômeno reprodutível que tem intervenção do acaso) para a busca de um modelo matemático que as explicasse. No entendimento de Coutinho (2007), observam-se aí os primeiros indícios de uma dualidade da noção de probabilidade que se dá em virtude do conflito entre a apreensão perceptiva das chances de realização de um evento (grau de credibilidade) e a relação entre resultados favoráveis e possíveis (proporção das chances).

Os cálculos desenvolvidos por Pascal e Fermat acerca da avaliação de chances de ocorrência de um evento são considerados um avanço em relação à avaliação intuitiva que se fazia anteriormente

Em 1713, foi publicado, postumamente o primeiro livro inteiramente dedicado a Teoria das Probabilidades de autoria de Jacob Bernoulli (1654-1705). “Ars Conjectandi”, mostra, o que vai ser ou deve ser a ciência Estatística. Foi nesta obra que Bernoulli inicia aplicação da probabilidade em outros contextos que não os de jogos de azar.

${ }^{3}$ Chevalier de Méré, conhecido como filósofo do jogo que também se interessou pelo uso da Matemática para determinar as apostas nos jogos de azar. 


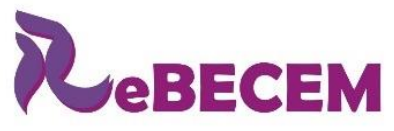

Segundo Coutinho (2007), Bernoulli coloca em evidência a dualidade do conceito de probabilidade que seria a razão entre números de casos ou estimativa de seu valor obtida pela observação da frequência experimental. Para avaliar uma probabilidade nesse contexto, Bernoulli propôs a determinação a posteriori da probabilidade de um evento esperado, após observação de um grande número de experiências semelhantes.

Com Bernoulli, podemos identificar uma nova maneira de estimar as chances de realização de um evento: o método experimental. Tal enfoque supõe que a probabilidade é um dado objetivo ligado ao evento e à experiência (COUTINHO, 2007, p. 62).

Uma outra importante contribuição de Bernoulli para a Estatística foi à "Distribuição de Bernoulli", que consiste em dizer que cada tentativa tem duas possibilidades de ocorrência chamadas: sucesso e insucesso (ex.: no lançamento de uma moeda ou sai cara ou coroa). Sendo assim, esta distribuição foi a base da distribuição binomial.

Foi no ano de 1812, que Pierre Simon Laplace (1749-1827), publicou o tratado "Teoria Analítica das Probabilidades", constituindo um grande marco da Teoria das Probabilidades. Neste tratado Laplace definiu probabilidade "como o número de vezes em que um dado acontecimento pode ocorrer, dividido pelo número total dos casos que podem acontecer, considerando-se que estes têm possibilidades iguais de acontecer". A partir de Laplace, as duas disciplinas Cálculo das Probabilidades e Estatística que até então haviam permanecido separadas, fundiram-se de maneira que o cálculo da Probabilidade constituiu a ferramenta matemática da Estatística, pela qual tomou impulso teórico.

Os jogos de azar baseados em dados, moedas, extração de bolas em urnas, enquadram-se na perspectiva teórica proposta por Laplace. Estes exemplos se fazem adequado por tratar de fenômenos cuja variável é discreta e porque se supõe possível selecionar, como espaço amostral, um conjunto de sucessos elementares que garantam a equiprobabilidade.

No entendimento de Coutinho (1994), os trabalhos desenvolvidos por PierreSimon Laplace colocaram a Probabilidade definitivamente no quadro matemático. Conforme a autora, Laplace acreditava num determinismo absoluto e desenvolveu seu modelo matemático baseando-se em dez princípios dispostos em axiomas e definições, traduzindo sua visão "pascaliana” (COUTINHO, 1994, p. 21).

As ideias de Jules Henri Poincaré (1854 - 1912), matemático francês, expressas em sua obra Cálculo de Probabilidades (1912) trazem uma contribuição muito importante 
DOI: http://dx.doi.org/10.33238/ReBECEM.2019.v.3.n.2.22625

para uma mudança qualitativa em relação às interpretações precedentes do acaso. Poincaré, apresenta o acaso como uma manifestação macroscópica de uma causa muito pequena que nos escapa e, para ele, o acaso não é objeto do cálculo de probabilidades. Coutinho (2007) afirma que temos com as ideias de Poincaré um enfoque do acaso sob um ponto de vista determinista. Vejamos um trecho que explicita um pouco de suas ideias:

É necessário que o acaso seja outra coisa que não o nome que damos à nossa ignorância, que entre os fenômenos dos quais ignoramos as causas, devemos distinguir os fenômenos fortuitos, sobre os quais o cálculo de probabilidades nos informará provisoriamente, daqueles que não são fortuitos e sobre os quais nada podemos dizer, enquanto não determinarmos as leis que o regem (POINCARÉ, 1912 apud COUTINHO, 2007, p. 6).

A axiomatização da teoria das probabilidades é fato recente na história da matemática, e data do ano de 1933, com a obra de Andrei Kolmogorov. Essa “axiomatização" surgiu em oposição às restrições mantidas na concepção clássica de Laplace (RODRIGUES, 2011, p.47).

Um novo enfoque da probabilidade (enfoque subjetivo) foi introduzido por Thomas Bayes, em um ensaio que foi publicado em 1763, dois anos após sua morte: a noção de probabilidade a priori, tendo observado uma consequência a posteriori (COUTINHO, 2007, p.15). Em Teoria da Probabilidade, o Teorema de Bayes mostra a relação entre uma probabilidade condicional e a sua inversa, por exemplo, a probabilidade de uma hipótese dada a observação de uma evidência e a probabilidade da evidência dada pela hipótese. Esse teorema representa uma das primeiras tentativas em modelar de forma matemática a inferência estatística. Vejamos um exemplo: a probabilidade de um evento A dado um evento B (probabilidade de alguém ter câncer de mama sabendo, ou dado, que a mamografia deu positivo para o teste) depende não apenas do relacionamento entre os eventos A e B (a precisão, ou exatidão, da mamografia), mas também da probabilidade marginal da ocorrência de cada evento. Bayes introduz assim duas noções de probabilidade: "a primeira, que buscamos estimar, é objetiva, a segunda apreciando o valor possível da precedente, colocada a priori, é subjetiva" (HENRY, 1994 apud COUTINHO, 2007, p. 15).

Após discorrer sobre os aspectos históricos e filosóficos da Teoria das Probabilidades, podemos inferir, que a ideia de acaso e indeterminismo, antes estranhas ao pensamento humano, foram, aos poucos, recebendo tratamentos matemáticos no sentido de construir explicações plausíveis para fatos, fenômenos e experimentos que se encontram no âmbito do aleatório os quais nos são apresentados ou vivenciados 


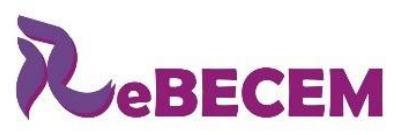

Revista Brasileira de Educação em

Ciências e Educação Matemática

DOI: http://dx.doi.org/10.33238/ReBECEM.2019.v.3.n.2.22625

diariamente. Essa trajetória histórica nos mostra também diferentes abordagens teóricas e, no caso de um estudo mais detalhado mostram-se a relação da Matemática com o acaso.

Nesse sentido, Lahanier-Reuter (1998) apud Rodrigues (2005) ressalta que a noção de acaso é variável. A autora cita alguns exemplos, tais como: Pascal trabalha com a ideia de acaso através de uma teoria de Igualdade, Laplace utiliza o conceito de acaso como irregularidade e, nos trabalhos de Fermat e Pascal têm-se a noção de acaso como algo definido convencionalmente e os efeitos possíveis de intervenção do acaso são em número finito e podem ser inteiramente descritos.

Nesta mesma linha, Coutinho (2007), nos informa que vários trabalhos de pesquisa sugerem uma "classificação" da noção de probabilidade segundo três enfoques: clássico (laplaciano), frequentista (Bernoulli) e bayesiano (subjetivo).

Diante destas considerações, mostra-se fundamental a identificação do contexto no qual o acaso é identificado para que se possa construir o significado do valor de probabilidade atribuído ao evento em estudo.

Mesmo que o acaso tenha sido "teorizado" pela matemática por meio desses autores em diferentes momentos históricos, as intuições que as pessoas têm de acaso, nem sempre, são compatíveis com os modelos matemáticos disponíveis. Ainda hoje persiste a crença em divindades e nas mais diversas explicações que as pessoas criam ou acreditam. Segundo Coutinho (2007), esse tipo de relação com o acaso, associando-o com a crença em intervenções divinas, é uma constante no comportamento humano ao longo do tempo.

Imbuído de suas crenças, muitas pessoas se lançam nos mais diferentes jogos de puro acaso, que oscila entre a vertigem do desconhecido e o cálculo de combinações sutis, entre a subjetividade humana e a ciência exata das probabilidades e estatísticas. Neste momento, os modelos matemáticos de cálculo de probabilidade são considerados em muitas circunstâncias como contra intuitivos e no ato do jogo, o jogador quer ter prazer em elaborar suas combinações originais e desafiar as leis do destino. Embora saiba que, a probabilidade de ganhar é pequena, há sempre essa possibilidade mágica de faturar o grande prêmio e, assim, se tornar rico instantaneamente, sem esforço! Com sorte, o feliz evento ocorre, mesmo que suas probabilidades de realização sejam pequenas. Acaso ou Modelos matemáticos, eis uma questão a se pensar! 


\section{Probabilidades e o acaso - a questão curricular}

Em relação à questão curricular no que concerne à probabilidades, de acordo com os Parâmetros Curriculares Nacionais - PCN, "as propostas elaboradas no período de 1980/1985, em diferentes países, apresenta, pontos de convergência” (BRASIL, 1997, p. 20), citando como exemplo, entre outros, "importância de se trabalhar com um amplo espectro de conteúdos, incluindo-se, já no ensino fundamental, elementos de estatística, probabilidade e combinatória, para atender à demanda social que indica a necessidade de abordar esses assuntos" (BRASIL, 1997, p. 21).

Nos PCN, foi incorporado oficialmente o "Tratamento da Informação" como um dos blocos de conteúdos da estrutura curricular de Matemática, indicando que "integrarão este bloco estudos relativos a noções de estatística, de probabilidade e de combinatória" (BRASIL, 1997, p. 40) e enfatizando que "o que se pretende não é o desenvolvimento de um trabalho baseado na definição de termos ou de fórmulas envolvendo tais assuntos" (BRASIL, 1997, p. 40).

Os conteúdos de Probabilidade acabaram ficando no então denominado "segundo ciclo" que inicialmente dizia respeito à $3 .^{\mathrm{a}}$ e $4^{\mathrm{a}}$ séries e depois, com a implementação do Ensino Fundamental de nove anos ${ }^{4}$, passou a contemplar $4 .^{\circ}$ e $5 .^{\circ}$ anos.

De acordo com os PCN, os objetivos para os $4 .^{\circ}$ e $5 .^{\circ}$ anos do Ensino Fundamental eram:

- Exploração da idéia de probabilidade em situações-problema simples, identificando sucessos possíveis, sucessos seguros e as situações de "sorte".

- Utilização de informações dadas para avaliar probabilidades (BRASIL, 1997, p. 61).

O documento, reafirmava a importância do trabalho com Probabilidades em vários trechos, como por exemplo,

É cada vez mais freqüente a necessidade de se compreender as informações veiculadas, especialmente pelos meios de comunicação, para tomar decisões e fazer previsões que terão influência não apenas na vida pessoal, como na de toda a comunidade. [...] Essa característica da vida contemporânea traz ao currículo de Matemática uma demanda em abordar elementos da estatística, da combinatória e da probabilidade, desde os ciclos iniciais (BRASIL, 1997, p. 84).

\footnotetext{
${ }^{4}$ A Lei $n^{\circ} 11.114$, de 16 de maio de 2005 - tornou obrigatória a matrícula das crianças de seis anos de idade no Ensino Fundamental e a Lei n⿳ 11.274, de 6 de fevereiro de 2006 - ampliou o Ensino Fundamental para nove anos de duração, estabelecendo como prazo para implantação 2010. Disponível em: http://portal.mec.gov.br/seb/arquivos/pdf/Ensfund/ensfund9_perfreq.pdf. Acesso em: 25 abril 2019.
} 
DOI: http://dx.doi.org/10.33238/ReBECEM.2019.v.3.n.2.22625

Embora o documento trouxesse a afirmação que ressaltava a importância do trabalho desde os ciclos iniciais, curricularmente a temática ficou de fora do ciclo de alfabetização.

Posteriormente, a Base Nacional Comum Curricular - BNCC - prevista na Constituição de 1988, na LDB de 1996 e no Plano Nacional de Educação de 2014, apontou como objetivo principal propor às redes de ensino e instituições escolares públicas e particulares uma referência nacional obrigatória para a elaboração ou adequação de seus currículos e propostas pedagógicas.

Relativo ao ensino de Matemática, a BNCC orienta-se pelo pressuposto de que a aprendizagem em Matemática está intrinsecamente relacionada à compreensão, ou seja, à apreensão de significados dos objetos matemáticos, sem deixar de lado suas aplicações (BRASIL, 2017, p.2 74). Nessa direção, o documento prescreve cinco unidades temáticas com seus respectivos objetos de conhecimento, qual seja: Números; Álgebra; Geometria; Grandezas e medidas e Probabilidade e estatística.

No que concerne ao estudo de noções de Probabilidade (objeto de reflexão deste artigo), para uma melhor compreensão do que propõe a BNCC, organizamos um quadro que mostra nos Anos Iniciais do Ensino Fundamental, os objetos de conhecimento com as habilidades que destacam a Probabilidade, dentro da Unidade Temática Probabilidade e Estatística:

Quadro 1: Correlação / Objeto de conhecimento e Habilidade

\begin{tabular}{|c|c|}
\hline \multicolumn{2}{|c|}{ Unidade temática / Probabilidade e Estatística } \\
\hline Objeto de conhecimento & Habilidade \\
\hline \multicolumn{2}{|r|}{$1^{\circ}$ ANO } \\
\hline Noção de acaso. & $\begin{array}{l}\text { (EF01MA20) Classificar eventos envolvendo o acaso, tais como } \\
\text { "acontecerá com certeza", "talvez aconteça" e "é impossível } \\
\text { acontecer", em situações do cotidiano. }\end{array}$ \\
\hline \multicolumn{2}{|r|}{$2^{\circ}$ ANO } \\
\hline $\begin{array}{l}\text { Análise da ideia de aleatório em } \\
\text { situações do cotidiano. }\end{array}$ & $\begin{array}{l}\text { (EF02MA21) Classificar resultados de eventos cotidianos aleatórios } \\
\text { como "pouco prováveis", "muito prováveis", "improváveis" e } \\
\text { "impossíveis". }\end{array}$ \\
\hline \multicolumn{2}{|r|}{$3^{\circ}$ ANO } \\
\hline
\end{tabular}


DOI: http://dx.doi.org/10.33238/ReBECEM.2019.v.3.n.2.22625

\begin{tabular}{|l|l|}
\hline $\begin{array}{l}\text { Análise da ideia de acaso em } \\
\text { situações do cotidiano: espaço } \\
\text { amostral. }\end{array}$ & $\begin{array}{l}\text { (EF03MA25) Identificar, em eventos familiares aleatórios, todos os } \\
\text { resultados possíveis, estimando os que têm maiores ou menores } \\
\text { chances de ocorrência. }\end{array}$ \\
\hline \multicolumn{2}{|c|}{$\mathbf{4}^{\text {o }}$ ANO } \\
\hline $\begin{array}{l}\text { Análise de chances de eventos } \\
\text { aleatórios. }\end{array}$ & $\begin{array}{l}\text { (EF04MA26) Identificar, entre eventos aleatórios cotidianos, aqueles } \\
\text { que têm maior chance de ocorrência, reconhecendo características de } \\
\text { resultados mais prováveis, sem utilizar frações. }\end{array}$ \\
\hline $\begin{array}{l}\text { Espaço amostral: análise de } \\
\text { chances de eventos aleatórios. }\end{array}$ & $\begin{array}{l}\text { (EF05MA22) Apresentar todos os possíveis resultados de um } \\
\text { experimento aleatório, estimando se esses resultados são igualmente } \\
\text { prováveis ou não. }\end{array}$ \\
\hline $\begin{array}{l}\text { Cálculo de probabilidade de } \\
\text { eventos equiprováveis. }\end{array}$ & $\begin{array}{l}\text { (EF05MA23) Determinar a probabilidade de ocorrência de um } \\
\text { resultado em eventos aleatórios, quando todos os resultados possíveis } \\
\text { têm a mesma chance de ocorrer (equiprováveis). }\end{array}$ \\
\hline
\end{tabular}

Fonte: BRASIL (2018, p. 278-297)

A BNCC ainda aponta que:

No que concerne ao estudo de noções de probabilidade, a finalidade, no Ensino Fundamental - Anos Iniciais, é promover a compreensão de que nem todos os fenômenos são determinísticos. Para isso, o início da proposta de trabalho com probabilidade está centrado no desenvolvimento da noção de aleatoriedade, de modo que os alunos compreendam que há eventos certos, eventos impossíveis e eventos prováveis. É muito comum que pessoas julguem impossíveis eventos que nunca viram acontecer. Nessa fase, é importante que os alunos verbalizem, em eventos que envolvem o acaso, os resultados que poderiam ter acontecido em oposição ao que realmente aconteceu, iniciando a construção do espaço amostral (BRASIL, 2018, p. 274).

Uma prática tal qual proposta nos documentos supracitados requer que se pense um contexto de aprendizagem que situe a criança em um ambiente de sala de aula, onde possibilite a aprendizagem, além de codificar e decodificar símbolos matemáticos, tabelas e gráficos a realizar diversas leituras de mundo. Além disso, poderá levantar conjecturas e validá-las, analisar dados e argumentar sendo capaz de compreender e justificar os procedimentos. Neste cenário, apontamos a alternativa de um trabalho com jogos, a qual será discutida brevemente abaixo.

\section{$4 O$ potencial dos jogos}

Os jogos podem ser utilizados segundo Grando (1995) para introduzir, amadurecer conteúdos, preparar o aluno para aprofundar os itens já trabalhados e inclusive para diagnosticar as dificuldades. Proposto de forma adequada, além dos 
DOI: http://dx.doi.org/10.33238/ReBECEM.2019.v.3.n.2.22625

conceitos, o jogo possibilita aos alunos desenvolver a capacidade de organização, análise, reflexão e argumentação, uma série de atitudes como: aprender a ganhar e a lidar com o perder, aprender a trabalhar em equipe, respeitar regras, entre outras (BRASIL, 2014, p.5). Além dessas inegáveis habilidades, por meio do jogo as crianças se manifestam espontaneamente, sem censura nem convenções, criam estratégias, buscam soluções e levantam hipóteses. Outro benefício é a socialização, que os jogos promovem, a fim de que as crianças aprendem a conviver e a respeitar as outras crianças e culturas.

Para que o ato de jogar na sala de aula se caracterize como uma metodologia que favoreça o ensino e a aprendizagem, alguns aspectos metodológicos são importantes de serem observados, quais sejam: Uma vez estabelecido os objetivos que se deseja alcançar é necessário escolher jogos adequados antes de colocá-los ao alcance das crianças. Escolhido o jogo é fundamental que o professor jogue e explore as possibilidades do mesmo. Também, na construção de um ambiente de aprendizagem é importante que as crianças sejam orientadas a trabalhar em grupo. A organização do espaço de sala de aula, deve ser tal que permita o professor se movimentar entre os grupos. O barulho é inevitável, porém, atentar-se para ele de forma construtiva, é necessário para que as crianças dialoguem durante o jogo. Outro aspecto importante é o registro das jogadas, assim as crianças podem pensar a respeito de suas estratégias. Ao final é essencial uma avaliação quanto aos objetivos alcançados, o que funcionou e o que poderia ter sido desenvolvido de maneira diferente.

Uma vez observado esses cuidados, certamente, as crianças se encarregarão do restante, como a diversão, por exemplo. Ao professor cabe observar como se dão as relações entre as mesmas, os conceitos e intervir sempre que necessário.

A seguir, apresentamos uma possibilidade, explorando o potencial do jogo, numa proposta que envolve acaso e probabilidade.

\subsection{O jogo Campeonato dos Números ${ }^{5}$}

O jogo que realizamos e hora apresentamos é visto como Jogo Didático, tal qual nos coloca Franco (1996) ao anunciar que o Jogo Educativo busca uma relação mediadora entre o lúdico e o educativo. A autora destaca, que o Jogo Educativo se transforma em Jogo Didático quando apresenta um "sentido restrito", ou seja, quando é utilizado como

\footnotetext{
${ }^{5}$ Releitura da proposta apresentada na tese de Campos (2017), uma das autoras deste artigo. Foi
} desenvolvido com crianças de 6 anos em uma escola Pública Municipal na cidade de Uberlândia. 


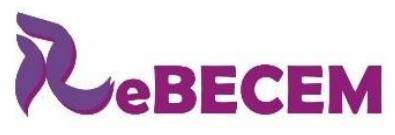

DOI: http://dx.doi.org/10.33238/ReBECEM 2019 v 3 n 2.22625

\section{Revista Brasileira de Educação em \\ Ciências e Educação Matemática \\ ISSN 2594-9179}

material ou situação que exige ações orientadas com vistas à aquisição de conhecimento de conteúdos específicos ou ao desenvolvimento de habilidades intelectuais.

Assim posto, "Brincar, jogar e aprender" com noções de Probabilidade, é a tônica central do jogo que tem como objetivo, introduzir noções primeiras de probabilidade, contagem e operações de adição.

Para redação do texto optamos por dividi-lo em 2 partes. Primeiramente apresentamos as regras do jogo e seu desenvolvimento, em seguida descrevemos as tarefas "Ampliando as possibilidades", buscando refletir sobre os saberes em movimento.

O jogo é composto de um tabuleiro do tipo 6 X 6, contendo todas as possíveis somas para o lançamento simultâneo de dois dados, marcadores suficientes para a quantidade de jogadores e dois dados (figura 1). Como há a repetição de determinadas somas, como por exemplo, “4 + 1", “ $1+4 "$, “ $3+2$ " e " $2+3$ ", esse resultado aparece mais vezes no tabuleiro.

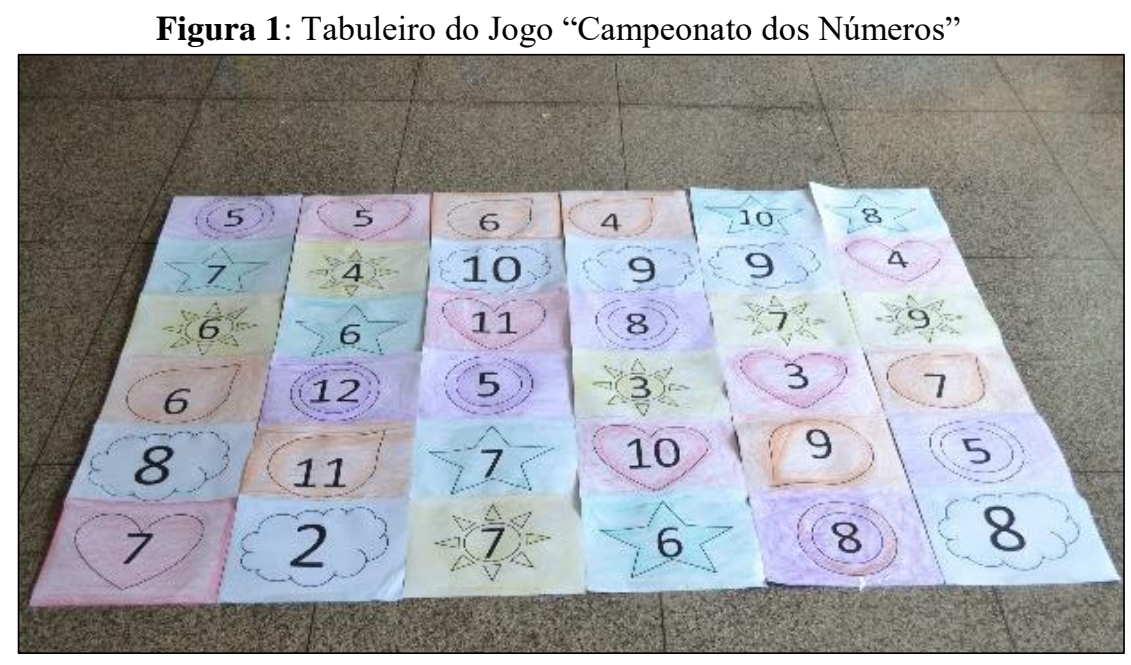

Fonte: Arquivo das pesquisadoras

Seu desenvolvimento acontece do seguinte modo:

1) O primeiro jogador lança os dois dados simultaneamente e soma os pontos obtidos;

2) Coloca o seu marcador na "casa" que indica a soma dos pontos obtidos;

3) Os próximos jogadores repetem o processo; se o resultado já tiver sido marcado o jogador passa a vez;

4) O vencedor será aquele que mais "casas" marcar.

A turma foi dividida em quatro equipes (azul, rosa, amarelo e laranja), mas antes do início do jogo, investigamos com as crianças o tabuleiro e as faces do dado e o fato 


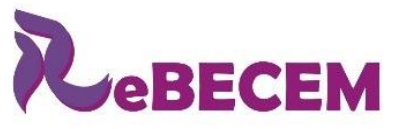

\section{Revista Brasileira de Educação em \\ Ciências e Educação Matemática}

DOI: http://dx.doi.org/10.33238/ReBECEM.2019.v.3.n.2.22625

de a soma dos pontos das faces opostas do dado ser sempre 7. Para que as crianças compreendessem as regras do jogo realizamos simulações de jogadas. Contudo, a regra "passa a vez", foi omitida durante o jogo, e ao chegar a essa situação, em que a casa pretendida já estivesse "ocupada", encaminhamos a discussão com novos questionamentos para uma nova investigação com estratégias alternativas. Depois, dessa investigação, a regra do jogo ficou compreendida. A partir desse momento, sempre que ocorria uma situação assim, as outras equipes comemoravam, pois já haviam inferido que, se uma equipe não colocasse o marcador, aumentaria a chance da outra ser vencedora. Durante todo o jogo, as crianças iam comparando a quantidade de marcadores das demais equipes para verificar sua situação no jogo (Figura 2).

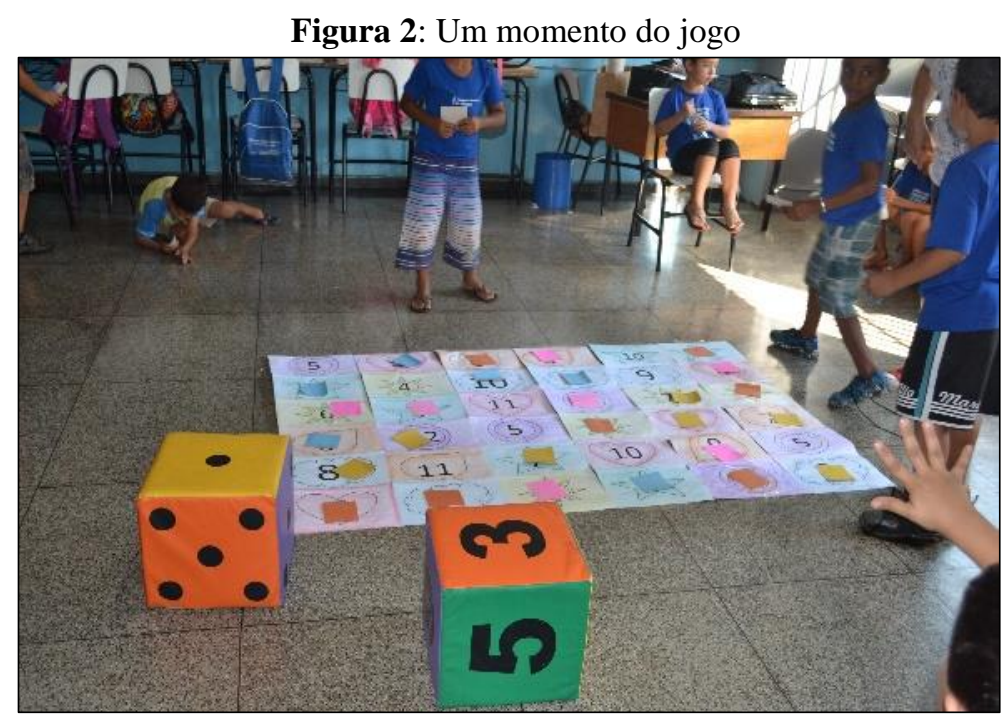

Fonte: Arquivo das pesquisadoras

Ao final do jogo, contamos coletivamente quantas casas foram marcadas por cada equipe, tendo como vencedor a Equipe Amarela.

Objetivando uma participação ativa na compreensão das regras, o jogo foi realizado primeiramente no coletivo, com toda a turma ao mesmo tempo, para em um próximo encontro a turma ser dividida em grupos menores.

Nesse sentido, construímos em conjunto com as crianças o tabuleiro, mas em escala menor.

As crianças conseguiram realizar o jogo com tranquilidade. Apesar de já terem jogado uma vez e de saberem que quando a casinha está marcada o jogador perde a vez, percebemos que as crianças ainda não se atentaram para quais números (somas) aparecem mais no tabuleiro. A torcida dos mesmos, era para conseguir nos dados uma soma mais alta. 
O sucesso do jogo foi tal, que as crianças pediram para levar para casa e poderem jogar com os pais e irmãos. Consideramos este um registro muito importante porque é importante a escola ultrapassar os seus muros, chegando de forma lúdica e pedagógica aos lares das crianças.

Durante o jogo sempre perguntávamos -quais números foram sorteados? Grande parte dos alunos tinha que contar o número de pontinhos (bolinhas é o termo usado pelas crianças) da face sorteada e, para a outra pergunta - Qual o resultado da soma do lançamento dos dois dados? Eles contavam novamente começando no primeiro dado e passavam para o segundo. Para a contagem, os alunos usavam os dedos das mãos. O momento de "marcar a casa no tabuleiro" também era debatido entre as crianças, uns falavam: - "coloca aqui", apontando para a casa escolhida por eles, outros falavam - "coloca ali", todos queriam apontar a sua escolha para a criança "marcadora" daquele instante.

O jogo permitiu a abordagem de noções primeiras de probabilidade (distribuição de probabilidade, quando discutimos o lançamento de um dado onde cada face tem equiprobabilidade de ocorrência que é 1/6,) espaço amostral (a representação no tabuleiro de todos as possíveis somas para o lançamento simultâneo de dois dados), noções de aleatoriedade. O desenvolvimento dessas habilidades estão expressas na BNCC, e devem ser trabalhadas no $3 .^{\circ}, 4 .^{\circ}$ e 5. ${ }^{\circ}$ ano, expressas no Quadro 1: Identificar, em eventos familiares aleatórios, todos os resultados possíveis, estimando os que têm maiores ou menores chances de ocorrência ((EF03MA25); Apresentar todos os possíveis resultados de um experimento aleatório, estimando se esses resultados são igualmente prováveis ou não(EF05MA22); e Determinar a probabilidade de ocorrência de um resultado em eventos aleatórios, quando todos os resultados possíveis têm a mesma chance de ocorrer (equiprováveis) (EF05MA23). 


\subsection{Ampliando as possibilidades do jogo}

\subsection{1 - Tarefa 1: Investigando o espaço amostral para as somas do lançamento simultâneo dos dois dados ${ }^{6}$}

Para suscitar a investigação fizemos algumas perguntas para as crianças: - O que significa esses números no tabuleiro? Será quantas "casinhas" tem no tabuleiro? Quais números aparecem no tabuleiro? A quantidade de números é igual ou diferente? Será quantos de cada? As crianças foram levantando suas hipóteses, abaixo um recorte das "falas das crianças"

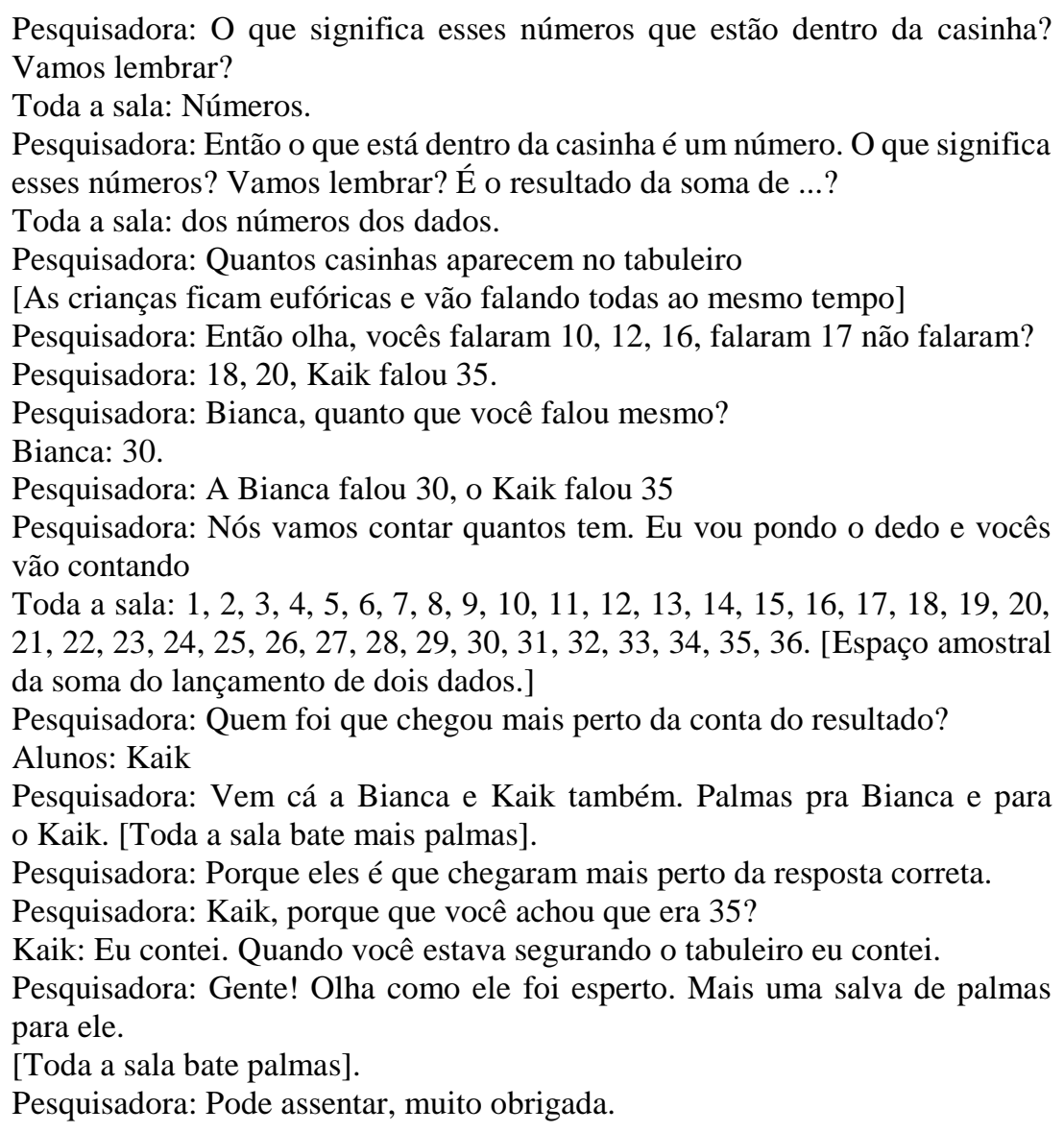

Essa tarefa possibilitou um momento de contagem do espaço amostral do lançamento de dois dados e também estimativa. Relativo ao trabalho com a estimativa, Turkel e Newman (1993) nos informam que este permite desenvolver a capacidade para reconhecer quando os números são razoáveis e fazem sentido. Essas ações aqui desenvolvidas conforme Turkel e Newman (1993, p.32) devem ser realizadas desde os

${ }^{6}$ Embora narradas sequencialmente, sem menção à questão temporal, as tarefas foram sendo desenvolvidas ao longo de algumas semanas e podem se encontradas com maior detalhamento em Campos (2017). 
DOI: http://dx.doi.org/10.33238/ReBECEM.2019.v.3.n.2.22625

primeiros anos quando as ideias de número são introduzidas. As autoras destacam que experiências de interpretações deveriam ser parte integrante das aulas de Matemática.

$\mathrm{O}$ item proposto para o segundo objetivo da tarefa foi o preenchimento de um quadro contendo colunas imagéticas das faces dos 2 dados e uma coluna para representar a soma. O objetivo foi representar de um modo lúdico o espaço amostral da soma do lançamento de dois dados. Na sequência solicitamos que as crianças pintassem "as somas" seguindo a aquarela de cores/soma (Figura 03). O objetivo foi investigar a distribuição da frequência das somas possíveis ao lançar simultaneamente dois dados. Para suscitar a discussão fomos lançando questões desafiantes, quais sejam: - Quantas somas encontraremos? Quantas somas iguais existem para o lançamento de dois dados? A resposta surgiu a partir da repetição das cores uma vez que cada cor representava uma soma.

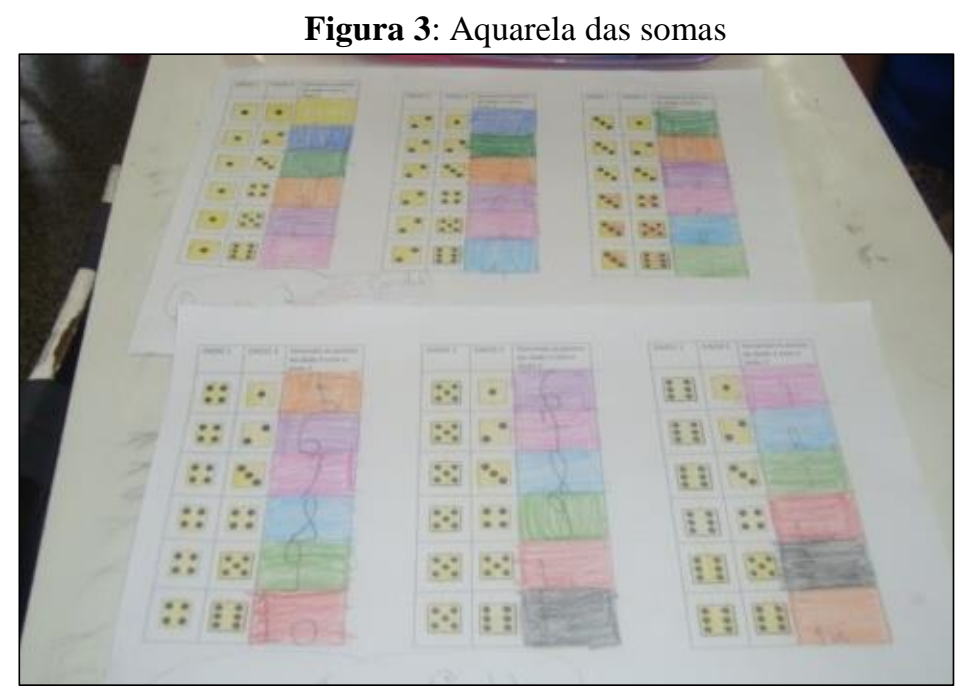

Fonte: Arquivo das pesquisadoras

Em função da idade das crianças (6 anos), essa foi a maneira "lúdica" que encontramos para substituir a tabela de dupla entrada ou o diagrama de árvore de possibilidades para o lançamento simultâneo de dois dados. As crianças não apresentaram nenhuma dificuldade na realização (exceto para as somas 11 e 12). Continuaram com o mesmo processo de contagem que haviam feito no jogo, qual seja, correspondiam cada pontinho do dado a um dedinho de sua mão e contavam quantos tinham ao todo.

\subsubsection{Tarefa 2: Avançando um pouco mais na investigação: a distribuição de frequência}

Para realização dessa tarefa, construímos coletivamente uma tabela de frequência. 
DOI: http://dx.doi.org/10.33238/ReBECEM.2019.v.3.n.2.22625

Durante o diálogo, as crianças foram anotando na tabela de duas colunas, em que a primeira representava a categoria "Soma" e a segunda, "quantas vezes cada soma apareceu". Fomos conduzindo, associando soma, cor e quantidade (as crianças tinham em mãos a tabela de cores/somas construída na aula anterior. Continuamos a investigação comparando as demais somas com frequências iguais. Ressalto que as crianças realizaram esta etapa sem dificuldades e se mostraram bastante interessada.

Pesquisadora: Agora olha quantos quatro aparece.

Crianças: Três, três.

Pesquisadora: Que cor que é mesmo o quatro?

Crianças: Verde escuro.

Pesquisadora: Verde escuro, quem não tiver sabendo como que é o quatro, procura pela cor, não tem problema, pela cor você identifica o 4. É só corresponder, a cor verde escura com o quatro.

Fomos dialogando tal como descrito no episódio acima, até chegar na soma 12 e completar pôr fim a tabela de frequência da soma do lançamento de dois dados. Quando as crianças divergiam na resposta, fazíamos questionamentos sobre quem estava certo e pedíamos que verificassem e discutissem, até que chegassem à resposta correta. Quando concluímos a construção uma criança nos surpreendeu com suas investigações, transcrevemos abaixo.

Episódio: A descoberta de José Antônio

José Antônio: Tia (é assim que as crianças dos anos iniciais chamam as professoras) vai indo e voltando.

Pesquisadora: Como?

José Antônio; É tia! vai subindo e quando chega no seis" (ele se refere a frequência da soma 7) ... "vai descendo de um em um".

Pesquisadora: Nossa! Que beleza, você entendeu direitinho José Antônio. Você deu o pulo do gato, hoje eu vou dormir feliz viu! Vai, quando chega aqui "óh", no 6, vai voltando. José Antônio você é um gênio, mas que coisa mais fofa. "Óh", é isso mesmo "óh", 1, 2, 3, 4, 5, 6. Olha então vai assim "óh”. Tchum, tchum, tchum sobe, sobe, sobe e chega até o seis, não é? Aí depois o que que acontece? Desce, desce, desce, desce, desce, desce, até o um. Então começa aqui pequenino, depois vem assim, depois vem mais um pouco, mais um pouco, mais um pouco, depois o que que acontece?

José Antônio: Vai descendo.

O que nos encantou foi o fato de uma criança de seis anos conseguir fazer uma inferência tão importante sem mesmo olhar para a construção gráfica. Ou seja, perceber a simetria na distribuição da frequência para a soma do lançamento de dois dados.

Continuamos a investigação comparando as demais somas com frequências iguais.

Pesquisadora: Vamos comparar a soma 2 com a 12? (As crianças não entenderam a pergunta). Renovamos a pergunta - Sandra: o que elas têm de igual ou diferente?

João Vitor: Ih! As duas tem um só (a soma 2 e a soma 12 só aparece uma vez). 


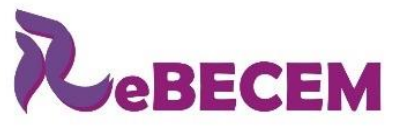

DOI: http://dx.doi.org/10.33238/ReBECEM.2019.v.3.n.2.22625

\section{Revista Brasileira de Educação em \\ Ciências e Educação Matemática}

Esta tarefa permitiu trabalharmos a distribuição de probabilidades e simetria intuitivamente, o que facilitará quando, no futuro as crianças forem estudar essas temáticas com rigor teórico.

\subsubsection{Tarefa 3: A Representação gráfica da frequência da soma do lançamento de dois dados}

Optamos por realizá-la de duas maneiras, quais sejam: a primeira por meio da construção com material manipulável e, a segunda, por meio da construção no ambiente “lápis e papel”.

Para a primeira representação, entregamos uma lata de alumínio (cada lata representava a ocorrência de uma soma) para as crianças preencherem as colunas da soma segundo a tabulação dos dados (Figura 04) do lançamento simultâneo de dois dados segundo a tabulação realizada na tarefa anterior. Fomos chamando as crianças para completar o gráfico. Este foi um momento bem animado e participativo e, ao final as crianças degustaram o refrigerante geladinho.

Figura 4: Construção do gráfico da distribuição da soma do lançamento simultâneo de dois dados

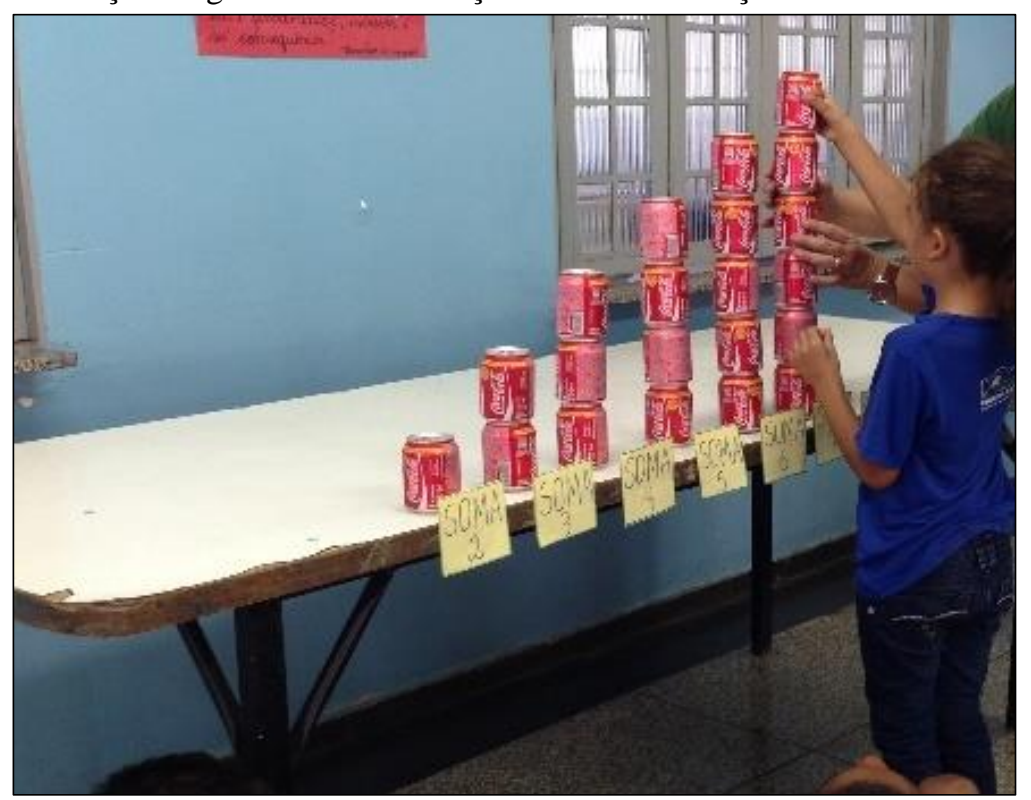

Fonte: Arquivo das pesquisadoras

Durante a construção do gráfico, apresentamos algumas questões para auxiliar as crianças a interpretarem a situação, qual seja: Quantas vezes a resultado 2 apareceu? ... e assim por diante, investigando cada uma das colunas; Quais são as colunas que tem o mesmo tamanho? Quais foram os resultados que menos apareceram? Qual foi o resultado 


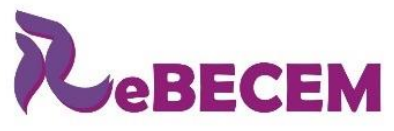

DOI: http://dx.doi.org/10.33238/ReBECEM.2019.v.3.n.2.22625

\section{Revista Brasileira de Educação em \\ Ciências e Educação Matemática \\ ISSN 2594-9179}

que mais apareceu? Quantos resultados são menores que 7? Quais são eles? Quantos resultados são maiores que 7? Quais são eles? ... e assim por diante.

Com essas questões foi possível as crianças perceberem nitidamente 0 termo "indo e vindo" utilizado por José Antônio durante as discussões dos resultados da tabela. Mostramos no gráfico este movimento da simetria da frequência das somas, as crianças concluíram que: "o sete divide no meio antes dele vai subindo e depois dele vai descendo do mesmo jeito", mostrando assim, de forma intuitivamente o conceito de simetria.

Para segunda representação, qual seja, construção no ambiente "lápis e papel", afixamos as latinhas em um papelão, para que pudéssemos fazer uma discussão sobre os resultados e as crianças tivessem uma referência para preencherem o gráfico no papel,

Através de uma folha de papel quadriculada, as crianças representaram a frequência da soma do lançamento de dois dados (figura 5 e 6), sempre observando o gráfico construído com as latinhas de alumínio.

Figura 5: Construção do gráfico da distribuição da soma do lançamento simultâneo de dois dados no ambiente lápis e papel

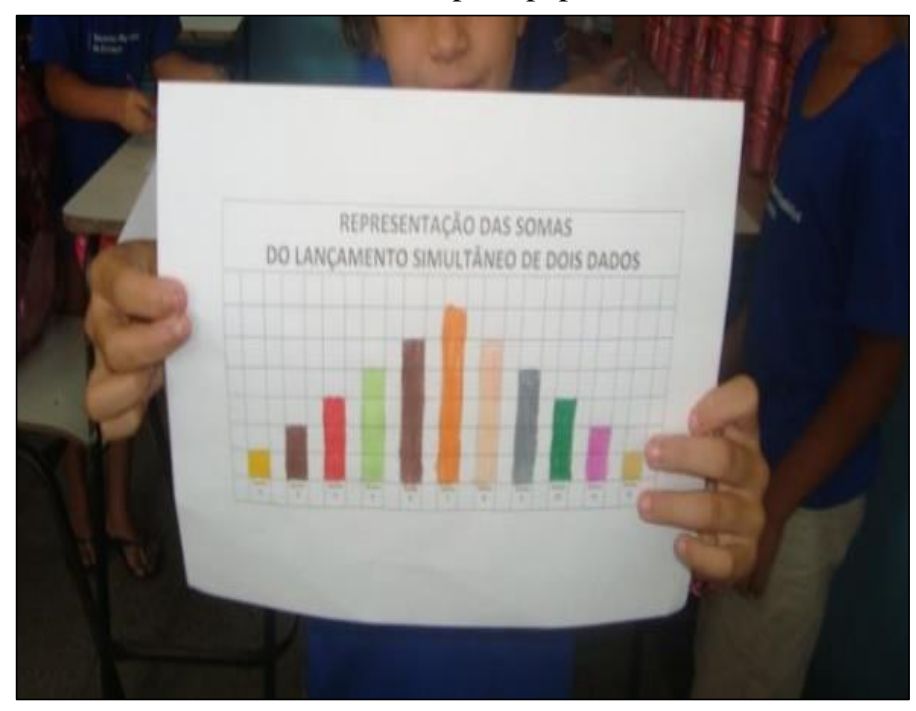

Fonte: acervo da pesquisadora 
DOI: http://dx.doi.org/10.33238/ReBECEM.2019.v.3.n.2.22625

Figura 6: Construção do gráfico da distribuição da soma do lançamento simultâneo de dois dados no papel

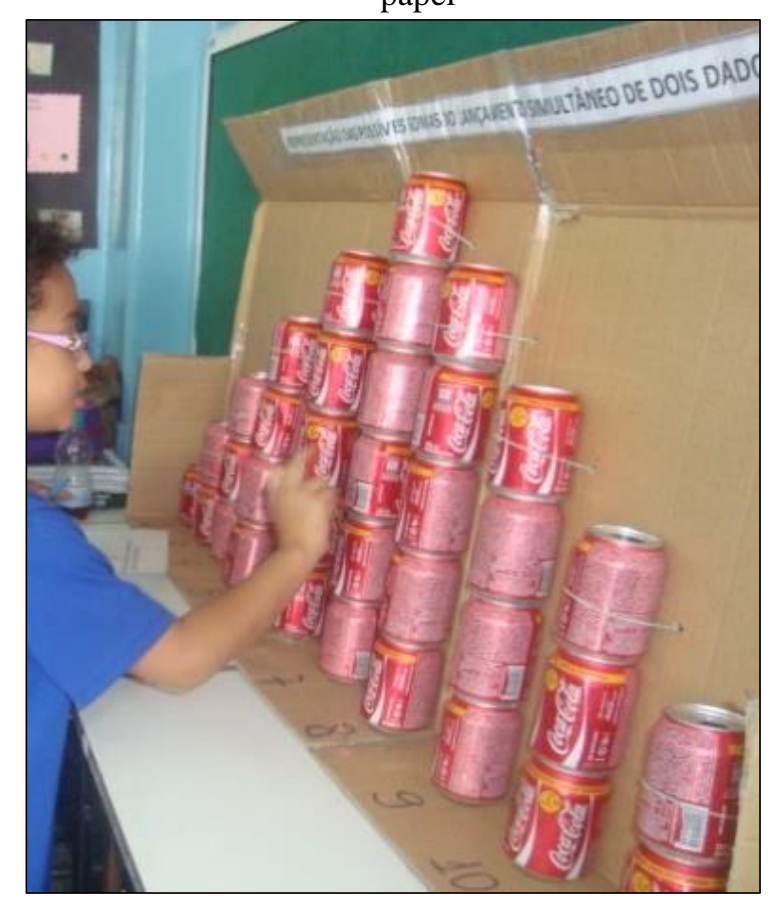

Fonte: acervo da pesquisadora

Para a discussão dos resultados organizamos uma roda de conversa tendo como referência os gráficos construídos. O diálogo com as crianças foi pautado na variabilidade dos dados. Por exemplo, quantas vezes a resultado 2 apareceu? Quais são as colunas que tem o mesmo tamanho?

A tarefa 3, permitiu a abordagem de diferentes conceitos Estatísticos, quais sejam: Tabulação dos dados e representação em forma de tabela (quantidade de pares que tem a mesma soma); Construção de gráficos (representação gráfica da frequência de cada soma); e discussão dos resultados (análise dos dados e/ou comportamento da frequência das colunas de Soma e observação no gráfico da simetria da frequência das somas tendo como referência a frequência da soma 7/eixo de simetria), embora nosso foco no artigo não seja as discussões que envolvem às habilidades relativas à Estatística.

\section{Algumas considerações}

A discussão envolvendo a questão curricular, proposta neste artigo, nos possibilita indicar que a elaboração e execução de uma prática tal qual proposta na BNCC, que permita discutir o acaso e a probabilidade com as crianças dos Anos Iniciais do Ensino Fundamental (1. ${ }^{\circ}$ ao $5 .^{\circ}$ ano), requer que se pense um contexto de aprendizagem que situe a criança em um ambiente de atividade matemática, estatística e probabilística (nosso destaque aqui), que possibilite que ela aprenda, além de codificar e decodificar os 
DOI: http://dx.doi.org/10.33238/ReBECEM.2019.v.3.n.2.22625

símbolos matemáticos, a realizar diversas leituras de mundo, levantar conjecturas e validá-las, analisar dados e argumentar.

Consideramos que o jogo e as tarefas de natureza investigativa apresentadas, envolvendo o jogo, durante seu desenvolvimento, contribuíram para o desenvolvimento de importantes noções iniciais de Probabilidade, quais sejam: distribuição de probabilidade, espaço amostral, noções de aleatoriedade, simetria da frequência das somas do lançamento de dois dados e que embora fossem realizadas com crianças de 6 anos, possibilitam trabalhos com todos os outros Anos do Ensino Fundamental, reafirmando seu potencial como mediador na construção do conhecimento.

Esperamos também contribuir com o conhecimento, planejamento e reflexão do professor que ensina Matemática, no que diz respeito à Estatística e Probabilidade, em especial à Probabilidade, mas que podem se entrecruzar com diversos outros assuntos/habilidades/conteúdos nos momentos da ação.

\section{Referências}

BRASIL. Ministério da Educação e do Desporto. Secretaria de educação fundamental. Parâmetros Curriculares Nacionais: matemática. Brasília: MEC/SEF, 1997.

BRASIL. Ministério da Educação. Secretaria de Educação Básica. Pacto nacional pela alfabetização na idade certa: Educação Estatística / Diretoria de Apoio à Gestão Educacional. Brasília: MEC, SEB, 2014.

BRASIL. Ministério da Educação. Base Nacional Comum Curricular. Brasília: MEC, 2017.

BRASIL. Ministério da Educação. Base Nacional Comum Curricular. Brasília: MEC, 2018.

CAMPOS, S. G.V.B. Sentido de número e estatística: uma investigação com crianças do $1^{\circ}$ ano do ciclo de alfabetização. 2017. Tese (Doutorado em Educação Matemática) - Instituto de Geociências e Ciências Exatas, Universidade Estadual Paulista "Júlio Mesquita Filho", Rio Claro, 2017.

COUTINHO, C. Q. S. Introdução ao conceito de probabilidade por uma visão frequentista. 1994. Dissertação (Mestrado em Educação) - Pontifícia Universidade Católica de São Paulo, São Paulo, 1994.

COUTINHO, C. Q. S. Conceitos probabilísticos: quais contextos a história nos aponta?

Revemat: Revista Eletrônica de Educação Matemática, Florianópolis v. 2, n. 1, p. 50-67, 2007. Disponível em: http://www.periodicos.ufsc.br/index.php/revemat/article/view/12991. Acesso em 15 jul. 2013.

FRANCO, A. O pensar e o jogo nas relações numéricas. 1. ed. Belo Horizonte: Editora Lê, 1996. 
DOI: http://dx.doi.org/10.33238/ReBECEM.2019.v.3.n.2.22625

GRANDO, R. C. O jogo e suas possibilidades metodológicas no processo ensino/ aprendizagem da Matemática. 1995. Dissertação (Mestrado em Educação) - Faculdade de Educação, Universidade Estadual de Campinas, Campinas.

RODRIGUES, J. M. S. Formação matemática de professores de atuação multidisciplinar nas séries iniciais do ensino fundamental: indicativos com vistas a estudos relativos a noções de probabilidade. 2005. Dissertação (Mestrado em Educação) - Setor de Educação, Universidade Federal do Paraná, Curitiba.

RODRIGUES, J. M. S. A probabilidade como componente curricular na formação matemática inicial de professores polivalentes. 2011. Tese (Doutorado em Educação) - Setor de Educação, Universidade Federal do Paraná, Curitiba.

SILVA, I. A. Probabilidades: a visão laplaciana e a visão frequentista na introdução do conceito. 2002. Dissertação (Mestrado em Educação) - Pontifícia Universidade Católica de São Paulo, São Paulo, 2002.

TURKEL, S.; NEWMAN C. M. Qual é o teu número? Desenvolvendo o Sentido de número. Revista Educação e Matemática, Lisboa, v. 1. n. 25, p.31-33, 1993.

Recebido em: 16 de junho de 2019.

Aceito em: 16 de agosto de 2019. 